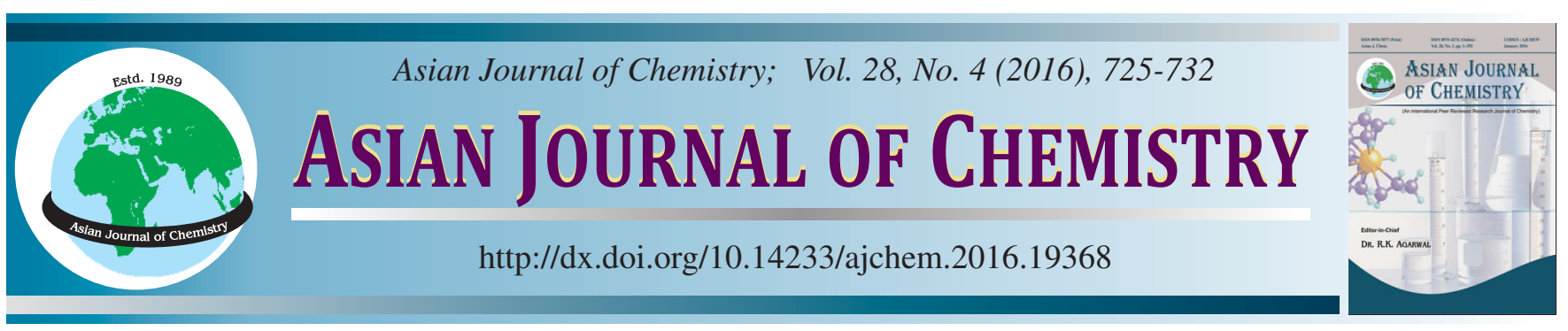

\title{
Waste Bleaching Clay for Biodiesel through Base Catalyzed Transesterification of Residual Cotton Seed Oil
}

\author{
Zeeshan Ali ${ }^{*}$, Amran Waheed, Hamid Iqbal and Syed Faheem Shah
}

Applied Chemistry Research Center, Pakistan Council of Scientific and Industrial Research Laboratories, Complex, Shahrah-E- Jalal-ud-Din Roomi Road (Ferozepure Road), Lahore-54600, Pakistan

*Corresponding author: Tel: +92 42 99230688-95; E-mail: drzeeshan2009@yahoo.com

\begin{abstract}
After processing of cotton seed oil the activated bleaching clay is converted to low valued waste bleaching clay. The chemical composition of activated bleaching clay from Mirpur, Pakistan is found out as; $\mathrm{SiO}_{2}(71.34 \%), \mathrm{Al}_{2} \mathrm{O}_{3}(15.54 \%), \mathrm{CaO}(2.72 \%), \mathrm{MgO}_{(1.48 \%),} \mathrm{Na}_{2} \mathrm{O}$ $(0.51 \%), \mathrm{K}_{2} \mathrm{O}(0.23 \%), \mathrm{Fe}_{2} \mathrm{O}_{3}(0.02 \%)$. The clay has bleachability $(74 \%)$ and oil retention $(32.70 \%)$ by standard method (ASTM). The cotton seed oil recovered with different polarity solvents (31.1-36.3\%) have different free fatty acid values (0.2-0.85). However, lower percentage of tri-esters $(88 \%)$ was found out in dark coloured recovered oil as compare to freshly $n$-hexane extracted cotton seed oil $(92.5 \%)$ from edible oil refinery. The lower free fatty acid $(0.2)$ valued cotton seed oil recovered with $n$-hexane is transesterified at optimized conditions to mono alkyl esters. The reaction was optimized by performing series of experiments to observe molar concentrations: methanol-oil (3-18 : 1), oil-catalysts $/ \mathrm{NaOH} / \mathrm{NaOCH}_{3} / \mathrm{KOH} / \mathrm{KOCH}_{3}(1.5-0.25)$, temperature $\left(20-80{ }^{\circ} \mathrm{C}\right)$, mixing intensity $(200-650 \mathrm{rpm})$ and reflux time $(120 \mathrm{~min})$. The maximum yield of biodiesel $(98.5 \%)$ has been found out by $\mathrm{NaOCH}_{3}(1.00 \%)$, methanol-oil (6:1) at $65^{\circ} \mathrm{C}$ and stirring intensity $(650 \mathrm{rpm})$. The properties of biodiesel are also under limits as per standards: ASTM 6751 , EN 14214 and optimal methylation of recoverd oil appeared to be an acceptable feedstock for production of biodiesel as renewable fuel.
\end{abstract}

Keywords: Renewable energy, Biofuel, Methylation, Transesterification, Methaoxides.

\section{INTRODUCTION}

Proper utilization of waste materials and byproducts is quiet important to fulfill demands of quality products and to substitute depleting resources of the world. As hydrocarbons of fossils being the conventional source of fuels are continuously decreasing, the fluctuating mineral oil prices and environmental impacts have intensified the search for alternate biofuels. Biofuels has attracted a great deal of interest during the past decade as a renewable, biodegradable, non-toxic and eco-friendly clean fuel [1]. Biodiesel is found to be the best substitute of petro-diesel fuel not only for its comparable calorific value but also for its several other advantages such as biodegradability, low toxic emission, higher flash point, excellent lubricity, carbon neutral and environmentally acceptance fuel [2]. The oils and fats are found to be the best candidates as an alternate and ecofriendly energy source. Oils and fats is not only used for edible purposes but varieties of industrial products are also developed from this commodity. However the use of edible sources comes under heavy criticism since 'fuel-forfood' concept is regarded as an unethical by many quarters. Alternatively, the use of waste edible oil could be a better solution as it is available in abundant [3]. Triglyceride for biodiesel production comes from various sources e.g., edible oil, inedible oil, waste/used oils, animal fats [4] and recently from microorganisms [5].

The consumption of edible oils/fats only in Pakistan is $2500 \mathrm{mmt}$. About $565 \mathrm{mmt}$ (23\%) of oils/fats requirements is met through oil seed cultivation and animal resources [6]. The cotton is a major crop of the country, cotton seed is the by product and cotton seed oil (CSO) is extracted from the seeds of the cotton plant after the removal of cotton lint. The country contributes about $10 \%$ of the total cotton seed oil produced all over the world [7]. Cotton (Gossypium hirsutum L.), belonging to the Malvaceae family is an important crop that yields the natural fibre used by the textile industry. It is one of the second best potential sources for plant proteins after soybean and the ninth best oil-producing crop [8]. The locally available bleaching clay is frequently used to process not only locally produced oils but also imported oils to meet the standards for edible usage. Bleaching clay are used in edible oil processing industries to remove colouring matters, soap, gums, metals (iron, nickel), oxidized compounds and polymers. This substance consists primarily of hydrated aluminium silicate, 
reports indicated that bleaching clay retains $20-40 \%$ of oil and importantly, the adsorbed oil represents the major part of bleaching cost as reported by Ong [9] The waste bleaching clay used for oil processing is being identified for fuel, it serves as important by product of oil processing industries. The activated bleaching clay have specific chemical composition, also contains impurities and unwanted materials. Large quantities of bleaching clay are disposed off in landfills, causes pollution hazard and the retained oils have higher acid values and moisture contents.

The direct use of oils and fats as fuel is also limited due to two main reasons; high viscosity and low volatility [2]. Therefore, oils and fats are chemically reacted with alcohols (transesterification reaction) to produce fatty acid alkyl esters/ biodiesel [10]. The resulting product not only contains alkyl esters but also unreacted starting material, residual alcohol and residual catalyst [11]. The optimization of transesterification reaction depends upon; catalyst type and concentration, methanol-oil molar ratio, reaction temperature, reaction time, stirring intensity, free fatty acid and moisture contents in oils and fats [12]. Mostly, transesterification is being carried out by alkaline catalysts in homogeneous phase i.e., $\mathrm{NaOH}, \mathrm{KOH}$, $\mathrm{NaOCH}_{3}$ and $\mathrm{KOCH}_{3}[13,14]$. The transesterification is also reported by enzymatic esterification of cotton seed oil [15]. However, no work has been carried out to study the base catalyzed transesterification of waste cotton seed oil from processed bleaching clay. Keeping in view, the consumption of fixed oils/fatty acids for production of edible oils, oleochemicals and allied products, the thorough investigation regarding base catalyzed transesterification of cotton seed oil recovered from waste bleaching clay has been carried out. The work includes the reaction parametric studies, biodiesel properties and economical comparison of biodiesel from cotton seed and waste bleaching clay.

\section{EXPERIMENTAL}

Activated bleaching clay of Mirpur, Pakistan and waste bleaching clay were attained from Hamza vegetable oil refineries, Lahore, Pakistan. Cotton seeds were purchased from Punjab Grain Market, Lahore, Pakistan. Solvents and reagents used in experimental work were of analytical-grade, mostly purchased from Merck-Darmstadt, Germany and Riedelde-Haën, Germany. Silica gel $\mathrm{HF}_{254}$, Merck Ref. 7739 was used for TLC and most of the mono, di and triacylglycerols' standards are product of $\mathrm{BDH}, \mathrm{UK}$. The $\mathrm{BF}_{3}$-methanol complex (Merck-Schuchardt, Germany) was used for fatty acids analysis through GLC. The standards methyl esters of fatty acids $\left(\mathrm{C}_{12}-\mathrm{C}_{24}\right)$ were attained from Supelco ${ }^{\circledR}$, USA for GLC analysis. The non-destructive locating reagent 2,7-dichlorofluorescein (Merck, Germany) used for coloured spots of different compounds under ultra violet light $(\lambda 366 \mathrm{~nm})$.

Evaluation of freshly extracted cotton seed oil: The analysis of freshly extracted cotton seed oil i.e., free fatty acid value/acid value, saponification value, iodine value, peroxide value, unsaponifiables was carried out by standard methods [16]. The glyceride components and fatty acids analysis were carried out by gas liquid chromatography (GLC) and thin layer chromatography (TLC) [17] The gas chromatograph; GC-14A and data processor C-R-4A was used for the identification of methyl esters by using a polar column $(2.5 \mathrm{~m} \times 3 \mathrm{~mm}$ id), coating material GP-10\%-SP-2330 on supporting media 100120 chromosorb WAW. The detector (FID) was used with requisite temperature of detector and injector at 250 and $230{ }^{\circ} \mathrm{C}$, respectively. It was operated under temperature programming $180-210{ }^{\circ} \mathrm{C}$ at the rate of $4{ }^{\circ} \mathrm{C} / \mathrm{min}$ and nitrogen flow rate of $30 \mathrm{~mL} / \mathrm{min}$. The fatty acid methyl esters were identified by the comparison of their corresponding retention times with standard methyl esters of fatty acids; $\mathrm{C}_{12}-\mathrm{C}_{24}$ under the same conditions [16].

Evaluation of activated bleaching clay: The analysis of activated bleaching clay i.e., compositional analysis, bleachability, moisture contents, oil filtration rate, oil retention and bulk density was carried out by standard methods [18].

Extraction of oil from waste bleaching clay and evaluation of cotton seed oil recovered: The lipids were extracted through cyclic solvent extraction (Soxhlet apparatus) by using solvents $n$-hexane, methanol, ethanol, petroleum ether and their combinations. Each process was repeated with fresh solvent for maximum extraction of lipids and extracts were pooled together in a round bottom flask. The solvent was removed under vacuum by rotary film evaporator (Hëidolph, Germany). The analysis of cotton seed oil recovered i.e., free fatty acid value/acid value, saponification value, iodine value, per oxide value, unsaponifiables was carried out [16]. TLC used to determine the lipid components and extent of transesterification reactions. The thin layer chromatograms (20 $\times 20 \mathrm{~cm}$ ) of $0.5 \mathrm{~mm}$ thickness were prepared by coating silica gel; $\mathrm{HF}_{254}$ (Merck Ref. 7739) for the separation/identification of lipid components. The plates were activated by heating at $105^{\circ} \mathrm{C}$ for $1 \mathrm{~h}$. The solvent system used for the separation of the different classes of neutral lipids was; hexane-diethyletheracetic acid (80/20/2) and for monoalkyl esters; hexane-diethylether (80/20). The non-destructive locating agent 2,7-dichlorofluorescein was used, which gave purple yellow coloured bands under an ultraviolet light at $\lambda 366 \mathrm{~nm}$.

Experimental procedure: Experiments were carried out to ascertain the methanol-oil molar ratio, catalyst type and concentration, reaction temperature and agitation intensity on transesterification reaction. The reaction time (120 min) was kept constant throughout experimental studies. The molar ratio of methanol-oil was varied as 3:1, 6:1, 9:1, 12:1, 15:1 and 18:1. The catalysts $\mathrm{NaOH}, \mathrm{NaOCH}_{3}, \mathrm{KOH}, \mathrm{KOCH}_{3}$ were used. Sodium methoxide $\left(\mathrm{NaOCH}_{3}\right)$ was found the most efficient catalyst so its concentrations were varied; 0.00, 0.25, 0.50, $0.75,1.00,1.25$ and $1.50 \%$ to found optimum concentration. The employed tempe-ratures were; $20,35,50,65$ and $80{ }^{\circ} \mathrm{C}$. Agitation rates were; 200, 350, 500 and $650 \mathrm{rpm}$.

Transesterification of cotton seed oil recovered: The chemical reaction was carried out using a $500 \mathrm{~mL}$ roundbottomed flask, equipped with thermostat, sampling outlet, mechanical stirrer (EYELA Tokyo, Japan) with tachometer reading $15 \times 10 \mathrm{rpm}$ DCM and reflux condensation systems. The cotton seed oil ( $250 \mathrm{~g}$ ) was preheated to the set temperatures; $20,35,50,65$ and $80^{\circ} \mathrm{C}$. The fixed amounts of freshly prepared methanolic solutions of catalysts e.g., sodium hydroxide, potassium hydroxide, sodium methoxide and potassium 
methoxide were mixed with oil and considered the time; 0.00 min. After consistent intervals, $2 \mathrm{~mL}$ of sample was withdrawn for chromatographic analysis. All the experiments were conducted for maximum of $120 \mathrm{~min}$ in order to ensure the complete esterification of cotton seed oil recovered into methyl esters.

Chromatographic analysis: The chromatographic techniques; TLC and GLC were frequently used for the analysis of trans-esterified oils. However for TLC analysis, the chromatograms $(20 \times 20 \mathrm{~cm})$ of thickness $(0.50 \mathrm{~mm})$ and adsorbent (silica gel $\mathrm{HF}_{254}$ ) were prepared by the use of Quickfit TLC applicator. The eluting solvent mixture $n$-hexane-diethylether (10:90) was used to fractionate and identify methyl esters/ glycerides in order to ensure the complete conversion of the cotton seed oil recovered into methyl esters. The non-destructive locating reagent 2,7-dichlorofluorescein used for coloured spots of esters and glycerides under ultra violet light $(\lambda 366 \mathrm{~nm})$.

Production, separation and purification of recovered oil methyl esters: After optimization of reaction parameters, the experiment was carried out to produce biodiesel by using $\mathrm{NaOCH}_{3}(1 \% \mathrm{w} / \mathrm{w})$, methanol-oil $(6: 1 \mathrm{w} / \mathrm{w})$, temperature $\left(65^{\circ} \mathrm{C}\right)$ and stirring intensity $(650 \mathrm{rpm})$ for maximum yield of biodiesel $(98.5 \%)$. On achieving the maximum yield of alkyl esters, the reaction stopped and the excess methanol was recovered with rotary film evaporator (Hëidolph, Germany) at $50{ }^{\circ} \mathrm{C}$ under vacuum. The residue transferred to separating funnel and washed with water $\left(50-55^{\circ} \mathrm{C}\right)$ and $n$-hexane. After, some time the mixture is cooled down and two phases are separated. The upper phase consisted of cotton seed oil recovered-monoesters while the lower phase contained the glycerol with other materials (methanol, catalyst, soaps and some entrained methyl esters and partial glycerides). After separation of the two layers by sedimentation, the upper methyl esters layer was purified by removing residual methanol at $50{ }^{\circ} \mathrm{C}$ by rotary film evaporator (Hëidolph, Germany) under vacuum. The remaining catalyst, methanol and glycerol were removed by successive rinses with distilled water. The residual water was removed by drying with anhydrous $\mathrm{Na}_{2} \mathrm{SO}_{4}$ overnight and filtered. The lower glycerol containing phase was treated with a calculated amount of sulfuric acid, to neutralize any unreacted sodium methoxide and to decompose the soaps formed during the transesterification reaction. The mixture obtained was heated for distillation at $65^{\circ} \mathrm{C}$ under vacuum to recover the excess methanol. So, the methyl esters (biodiesel) was seperated from glycerol and soaps. The biodiesel yield was determined as:
Product $(\%)=$ trans-ester $(\mathrm{g}) /$ Recovered oil $(\mathrm{g}) \times 100$

Analysis of CSOR-FAME (biodiesel): The fuel properties of recovered oil methyl esters i.e., acid value, density, kinematic viscosity $\left(40{ }^{\circ} \mathrm{C}\right)$, cloud point, pour point, flash point, ash content, copper strip corrosion test, ester contents, free/toal glycerine, mono/di/tri-glyceride contents were determined according to ASTM/EN methods [18].

Statistical analysis: The quality parameters of transesterified product was conducted in triplicate and the data are reported as mean \pm standard deviation $(\mathrm{SD})$.

\section{RESULTS AND DISCUSSION}

The indigenous bleaching clay is frequently processed to produce activated bleaching clay. The chemical composition and processing technology to produce activated bleaching clay determines its quality. The activated bleaching clay is analyzed by ASTM methods [18], the prominent chemical components of clay are silica $71.34 \%$, calcium oxide $15.54 \%$, magnesium oxide $2.72 \%$, sodium oxide $1.48 \%$ and specific quality parameters of clay i.e., bleachability $74 \%$, oil filtration rate 4.5 , oil retention $29.7 \%$ and bulk density 640 (Table-1). The composition of clay resembles to bentonite and falls under good category for the bleaching of vegetable oils. The oil retention is usually depends upon the chemical composition, structure, mesh size, physical parameters, activation process of clay and nature of oil. The bleaching process, impurities and waste bleaching clay retention time leads to the quantity and quality of cotton seed oil recovered.

The cotton seed oil are recovered from waste bleaching clay with polar and non-polar solvents, the accumulated oil yields (37.2-39.8 \%) with combination of solvents are higher due to different conditions of process in the oil refineries. The colour of polar extractions was also darker (brown) than that of the non-polar extractions. The polar solvents yielded more oil as compare to non-polar due to higher solubility of impurities and unwanted materials. The oil yields extracted with different solvents with respect to solvent cycles and free fatty acid of cotton seed oil recovered are shown in Fig. 1.

The ethanol yields more as compare to methanol and nonpolar solvents, in agreement with previous work [20]. The oil extracted with $n$-hexane is comparatively cleaner, pure, have less impurities, having less free fatty acids (0.32) and it is generally used in oil extraction units and refineries. So, $n$-hexane extracted oil is being considered for transesterification and for whole proceeding discussion. Although cotton seed (CS)

TABLE-1

PHYSICO-CHEMICAL CHARACTERISTIC DATA OF ACTIVATED BLEACHING CLAY

\begin{tabular}{ll|ll|lc}
\hline \multicolumn{2}{c|}{ Chemical composition } & \multicolumn{1}{c|}{ Physical analysis } & \multicolumn{2}{c}{ Sieve analysis } \\
\hline Silica $\left(\mathrm{SiO}_{2}\right)$ & 71.34 & Bleachability $(\%)$ & 74 & -100 & 100.00 \\
Iron Oxide $\left(\mathrm{Fe}_{2} \mathrm{O}_{3}\right)$ & 0.02 & Moisture $\left(100 \pm 2{ }^{\circ} \mathrm{C}\right)$ & 2.85 & -150 & 99.85 \\
Aluminium $\mathrm{Oxide}\left(\mathrm{Al}_{2} \mathrm{O}_{3}\right)$ & 15.54 & pH & 3.45 & -200 & 99.78 \\
Calcium Oxide $(\mathrm{CaO})$ & 2.72 & Free acid $($ as $\mathrm{HCl})$ & 1.26 & -250 & 99.09 \\
Magnesium Oxide $(\mathrm{MgO})$ & 1.48 & Oil filtration rate $\left(100 \pm 2{ }^{\circ} \mathrm{C}\right)$ & 4.50 & -300 & 98.57 \\
Sodium Oxide $\left(\mathrm{Na}_{2} \mathrm{O}\right)$ & 0.51 & Oil retention & 29.70 & -325 & 98.18 \\
Potassium $\mathrm{Oxide}_{2}\left(\mathrm{~K}_{2} \mathrm{O}\right)$ & 0.23 & Loose bulk density & 480 & -350 & 90.73 \\
Sulphur $\left(\right.$ as $\left.\mathrm{SO}_{3}\right)$ & $\mathrm{Nil}$ & Compact bulk density & 640 & & \\
Loss on ignition $\left(1000 \pm 5{ }^{\circ} \mathrm{C}\right)$ & 4.82 & & & \\
\hline
\end{tabular}

Values are means of triplicate determinations. 
TABLE-2

EXTRACTION OF RESIDUAL COTTON SEED OIL FROM WASTE BLEACHING CLAY WITH DIFFERENT SOLVENTS/COMBINATIONS

\begin{tabular}{|c|c|c|c|c|c|}
\hline $\mathrm{I}^{\mathrm{st}}$ Solvent & $\mathrm{I}^{\mathrm{st}}$ Extract* & Free fatty acid & II $^{\text {nd }}$ solvent & II ${ }^{\text {nd }}$ extract* & Total extract* \\
\hline \multirow{2}{*}{ Hexane } & \multirow{2}{*}{$35.0 \pm 0.5$} & \multirow{2}{*}{0.20} & Methanol (A) & $3.7 \pm 0.7$ & 38.7 \\
\hline & & & Ethanol (B) & $4.6 \pm 0.8$ & 39.6 \\
\hline \multirow{2}{*}{ Methanol } & \multirow{2}{*}{$27.5 \pm 0.3$} & \multirow{2}{*}{0.78} & Petroleum ether $(\mathrm{C})$ & $9.8 \pm 0.9$ & 37.3 \\
\hline & & & Hexane (D) & $11.3 \pm 0.7$ & 38.8 \\
\hline \multirow{2}{*}{ Ethanol } & \multirow{2}{*}{$39.4 \pm 0.4$} & \multirow{2}{*}{0.85} & Petroleum ether (E) & $0.2 \pm 0.05$ & 39.6 \\
\hline & & & Hexane $(F)$ & $0.4 \pm 0.07$ & 39.8 \\
\hline \multirow{2}{*}{ Petroleum ether } & \multirow{2}{*}{$33.2 \pm 0.6$} & \multirow{2}{*}{0.72} & Methanol (G) & $4.0 \pm 0.5$ & 37.2 \\
\hline & & & Ethanol $(\mathrm{H})$ & $6.1 \pm 0.7$ & 39.3 \\
\hline
\end{tabular}

*Percentage based on clay weights and all the extracts were collected after 24 cycles.

${ }^{\text {b }}$ Deoiled, dried clay from $1^{\text {st }}$ extraction is subjected to $2^{\text {nd }}$ extraction with the listed solvents

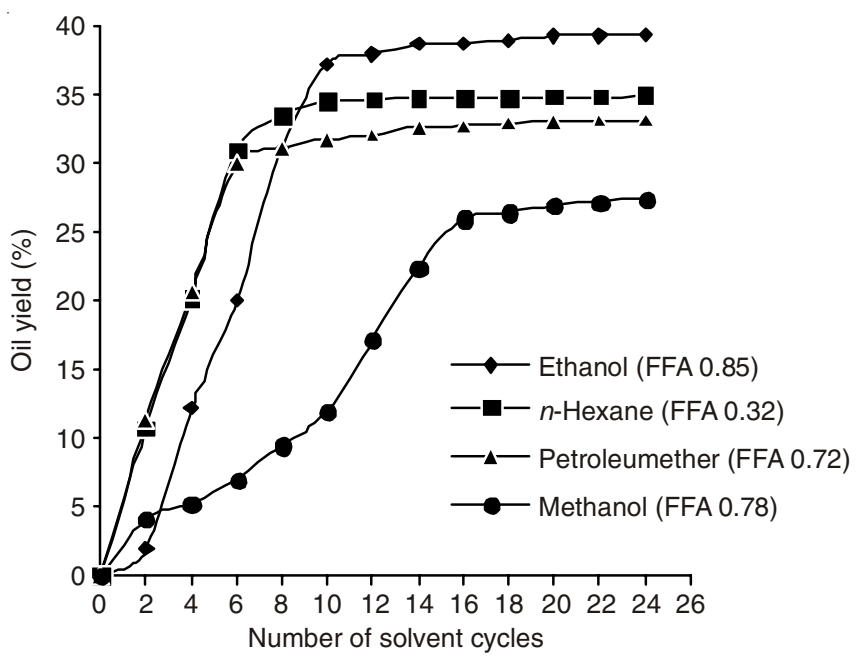

Fig. 1. Clay oil yields by different solvents with respect to solvent cycles and extraction time

is the by-product of crop but it is equally important being oil seed crop. The oil yield (39\%) found out by common solvent ( $n$-hexane) is comparable to previous work (30-45\%) [21]. The cotton seed oil yield is near to recovered oil (35\%) extracted by $n$-hexane (Table-2), there is also not much difference in bulk densities of seeds and wasted clay.

Table-3 shows the comparison of recovered oil and seed oil. The physico-chemical values and glycerides components determined by TLC are also comparable (Table-3), except difference in colour on Lovibond scale. The unsaponifiables of recovered oil are higher as compared to seed oil. The present results support the fact that seed oil recovered have higher values of colour index and unsaponifiables as compare to raw cotton seed oil due to higher contents of colouring components, carotenoids, phospholipids, gossypol and sterols. Although, cotton seed oil recovered have impurities but it contains comparable percentage of glycerides $(96.3 \%)$ to glycerides of cotton seed oil (98.2\%) as determined by TLC.

The $n$-hexane extracted cotton seed oil recovered is transesterified to produce biodiesel, the reaction variables contributing towards the conversion of recoverd oil into methyl esters were evaluated. The transesterification's variables studied were types of basic catalyst, amount of catalyst, molar ratio of methanol to oil, reaction temperature and agitation intensity. All the reactions were performed under the same reaction conditions, in order to compare the results with different basic catalysts;

\begin{tabular}{lcc}
\multicolumn{3}{c}{ TABLE-3 } \\
\multicolumn{3}{c}{ PHYSICO-CHEMICAL COMPARISON OF EXTRACTED OILS ${ }^{*}$} \\
\hline \multicolumn{1}{c}{ Tests } & Waste clay oil & Cotton seed oil \\
\hline Oil yield (\%) & 35.0 & 39.0 \\
Specific gravity $\left(25^{\circ} \mathrm{C}\right)$ & 0.9176 & 0.9170 \\
Colour (Lovibond- $1 ")$ & $90 \mathrm{Y}, 18 \mathrm{R}$ & $78 \mathrm{Y}, 7 \mathrm{R}$ \\
Refractive index $\left(40^{\circ} \mathrm{C}\right)$ & 1.4700 & 1.4680 \\
Free fatty acid $(\%$ as oleic acid) & 0.20 & 0.25 \\
Unsaponifiables $(\%)$ & 2.73 & 1.21 \\
Peroxide value (meq $\left.\mathrm{Kg}^{-1}\right)$ & 5.5 & 4.56 \\
Iodine value & 110 & 111 \\
Saponification value & 196 & 193 \\
Triglycerides $(\%)$ & 88.3 & 92.5 \\
Diglycerides $(\%)$ & 5.7 & 3.9 \\
Monoglycerides $(\%)$ & 2.3 & 1.8 \\
\hline " $n$-Hexane extracted oil from waste clay and cotton seeds.
\end{tabular}

$\mathrm{NaOH}, \mathrm{CH}_{3} \mathrm{ONa}, \mathrm{KOH}$ and $\mathrm{CH}_{3} \mathrm{OK}$ and their concentrations $(0.25-1.50 \% \mathrm{w} / \mathrm{w})$. The previous work showed that the vegetable oils yield higher percentages of methyl esters for alkaline catalysts at temperature greater than $60{ }^{\circ} \mathrm{C}$, molar ratios of methanol to oil was atleast 6:1 and minimum reaction time was $1 \mathrm{~h} \mathrm{[21].}$

Effects of different basic catalyst and amounts on transesterification of recovered oil: The efficiency of different basic catalysts is illustrated in Fig. 2. KOH showed the least amount of recovered oil methyl esters yield, while the highest yield of methyl esters is attained by using $\mathrm{CH}_{3} \mathrm{ONa}$. Sodium and potassium methaoxides exhibited higher yields (Fig. 3) as compare to hydroxides, the lower yield of esters by using hydroxide catalysts is may be due to formation of water which leads to hydrolysis of esters [22]. The best yields were found at concentration of $1.00 \%$. The lowest concentration of sodium methaoxide i.e., $0.25 \%$ was not effective to catalyze the reaction for maximum yield of products. The transesterification activity was not found out at zero percent catalyst concentration in the present studies. The conversion did not increase by increasing the catalyst amount greater then $1.00 \%$ and for compliance with biodiesel standards. It was observed that with the increase standards. It was observed that with the increase in catalyst concentration above $1.00 \%$, the yields were lower. The overload of sodium methaoxide emulsified the product. With the increase in the concentration of catalyst above $1.00 \%$ there was decrease in the yield of methyl esters. This decline in ester yield might be attributed to the increased formation of glycerol and soap. The current work agree with the results 


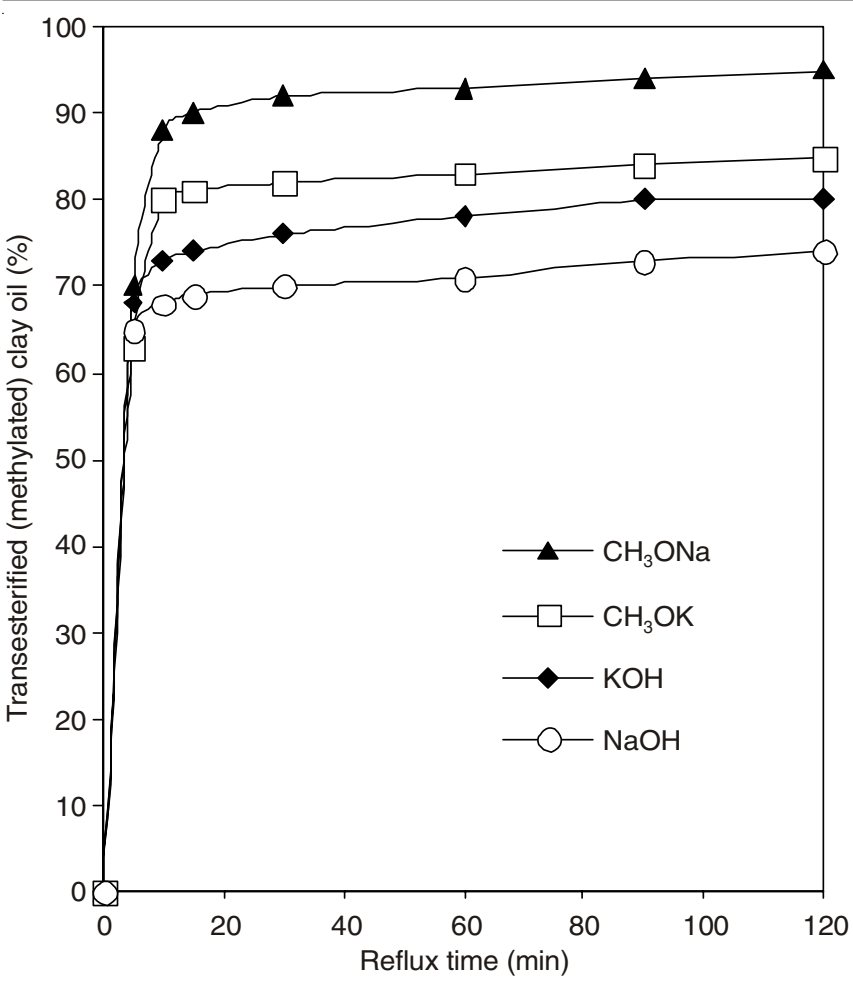

Fig. 2. Behaviour of different base catalysts on yield of recovered oil methyl esters at oil-methanol molar ratio (1:6), rate of stirring (650 rpm), reaction temperature $\left(65^{\circ} \mathrm{C}\right)$ and catalyst concentration (equimolecular)

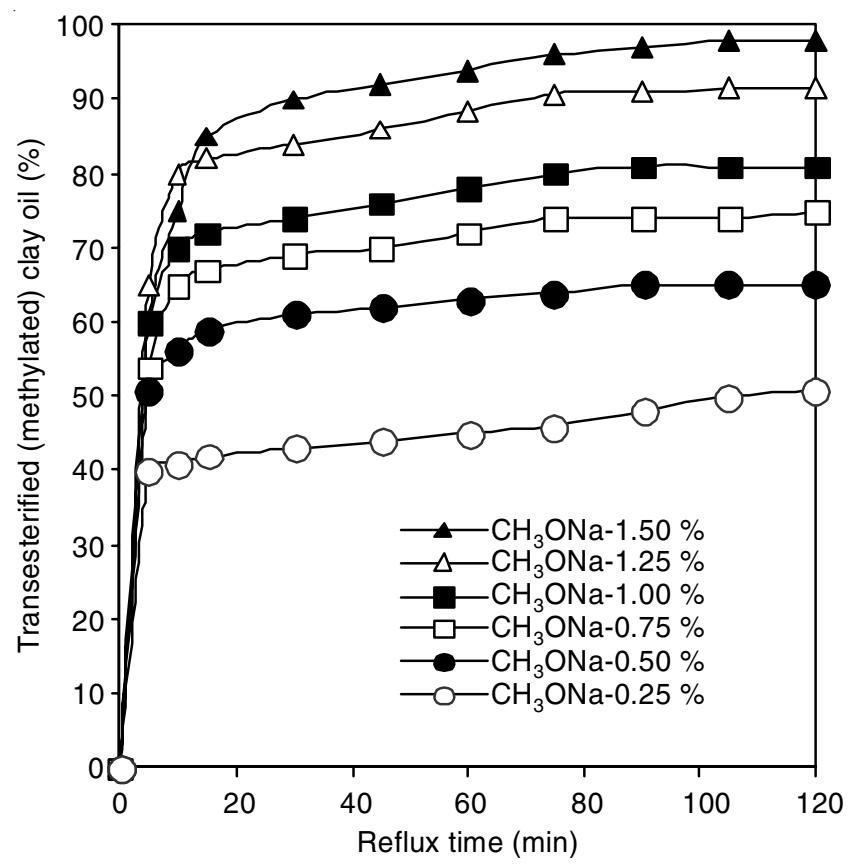

Fig. 3. Effect of Sodium methaoxide concentration on yield of recovered oil methyl esters at oil-methanol molar ratio (1:6), reaction temperature $\left(65^{\circ} \mathrm{C}\right)$ and rate of stirring $(650 \mathrm{rpm})$

that the formation of soap in the presence of higher amount of catalysts increases the viscosity of the reactants thus lowers the ester yield $[23,24]$. The addition of an excessive amount of alkaline catalyst causes formation of emulsions, increasing viscosity and making recovery of the methyl esters difficult $[25,26]$. This hinders the glycerine separation and as a result saponification consumes the base catalyst and reduces product yields. An optimal catalyst concentration is required for successful transesterification, in the present case it is determined to be $1.00 \%$ sodium methaoxide. However, it eas found that potassium hydroxide $(1.00 \%)$ offered the best yield during the methanolysis of Pongamia pinnata oil [27] and used frying oil [28]. Such variations in catalyst type and reaction might be attributed to the varied chemical nature of the oils and its components.

Effect of methanol/oil molar ratio on transesterification of recovered oil: Stoichiometrically, the transesterification reaction requires $3 \mathrm{~mol}$ of alcohol for $1 \mathrm{~mol}$ of triglyceride to yield 3 mol of methyl esters and $1 \mathrm{~mol}$ of glycerol.

Transesterification is a reversible/equilibrium reaction. Therefore an excess methanol is required for successful completion of reaction. The molar ratios of methanol to oil; $3: 1$, $6: 1,9: 1,12: 1,15: 1$ and 18:1 have been employed to determine the effects of excess methanol quantities. The yields of methyl esters with respect to time at different molar ratio of methanoloil from 3:1 up to the level of 18:1 exhibited encouraging effects on the yield of esters (Fig. 4). The higher molar ratio then the stoichiometeric value resulted in a greater ester formation [29] and could ensure complete reaction. The limited effect on the ester yield was found with the increase in molar ratio of methanol to oil. On the other hand, the reaction was also incom-plete for a molar ratio less then $6: 1$. It has been shown that beyond the molar ratio of $6 ; 1$, further methanol addition had no considerable effect on ester formation. Excess amount of catalyst also complicate ester recovery and raised process cost [30]. Incase of molar ratios greater than 6:1, a dilution effect is likely cause, while for molar ratios less than $6: 1$, insufficient mixing of the reactants in the biphasic transesterification reaction system is likely cause. The current results of optimum yield (98.5\%) of biodiesel with oil/ methanol molar ratio of 1:6 are in agreement with previous studies [12,26], which reported optimum conversion of various vegetable oils with a molar ratio of 1:6.

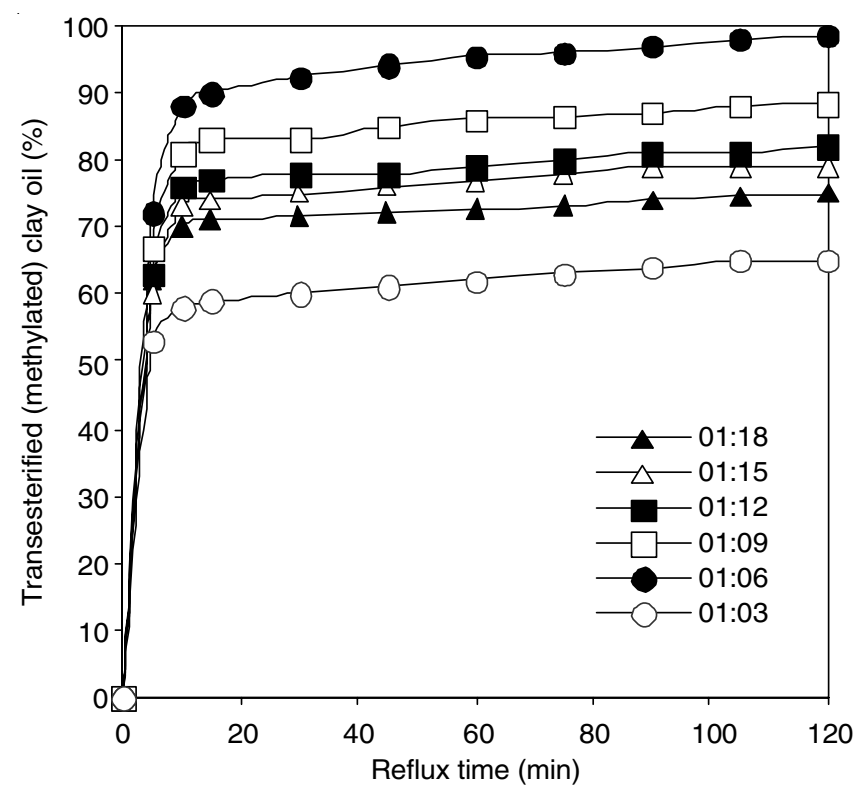

Fig. 4. Effect of oil-methanol molar ratio on recovered oil transesterification and biodiesel yield at $\mathrm{NaOCH}_{3}(1.00 \%)$, rate of stirring $(650 \mathrm{rpm})$ and reaction temperature $\left(65^{\circ} \mathrm{C}\right)$ 
Optimization of reaction temperature: The transesterifications of recovered oil were studied at different temperatures i.e., 20, 35, 50, 65 and $80^{\circ} \mathrm{C}$. The reaction time of $120 \mathrm{~min}$ was constant for each experiment.

The sodium methaoxide $(1.0 \%)$ as optimized in the previous section, methanol/oil molar ratio (6:1) and rate of stirring $650 \mathrm{rpm}$ were applied for each experiment at different temperatures. Fig. 5 showed that $85 \%$ ester yield was achieved in just $15 \mathrm{~min}$. After $120 \mathrm{~min}$, the reaction was completed and esters yields: $89.0,95.5,98.5$ and $98.7 \%$ were found out at $20,35,50,65$ and $80{ }^{\circ} \mathrm{C}$, respectively. The lower ester yields cannot be up to the standards due to higher contents of glycerides and fatty acids. The results are in accordance to previous work [31] that correlated reaction temperature and time. Therefore, an efficient transesterification of recovered oil may be carried out at $65{ }^{\circ} \mathrm{C}$, which is near to previous findings $[32,33]$.

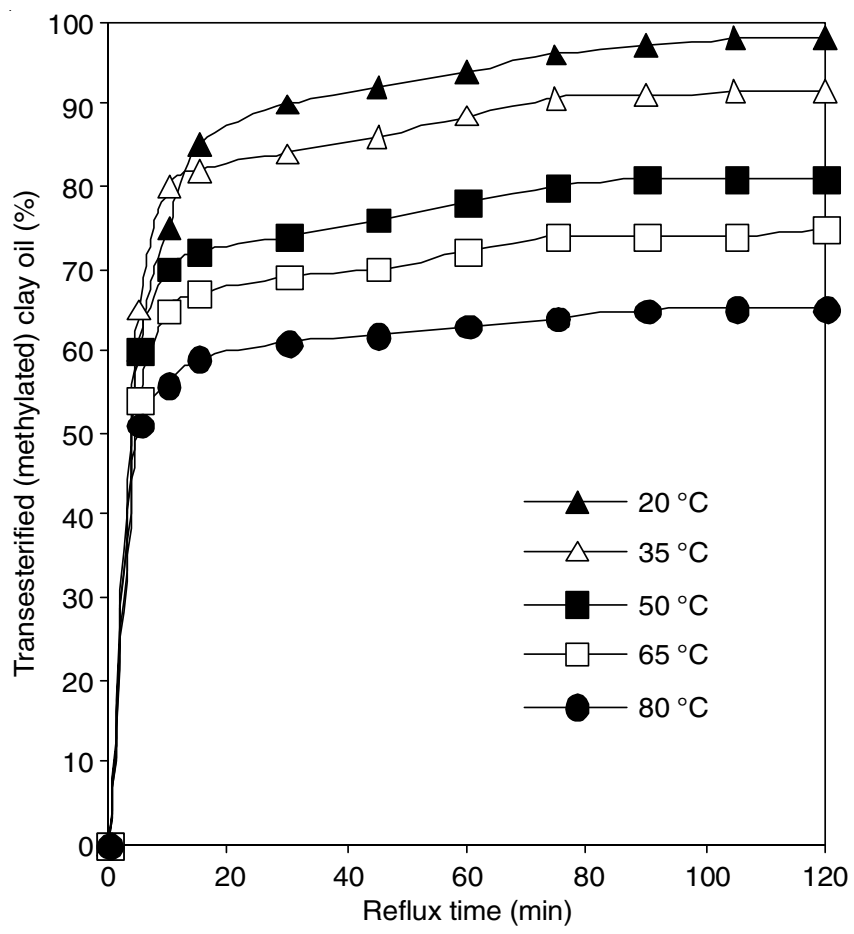

Fig. 5. Temperature effects on biodiesel yield at $\mathrm{NaOCH}_{3}(1.0 \%)$, oil $/$ methanol molar ratio (1:6) and rate of stirring $(650 \mathrm{rpm})$

Optimization of stirring rate: The effect of stirring on transesterification reactions was investigated by performing four experiments at different stirring rates $(200,350,500$ and $650 \mathrm{rpm})$. In all experiments, an oil/methanol molar ratio of $1: 6$, a reaction temperature of $65^{\circ} \mathrm{C}$ and $\mathrm{NaOCH}_{3}$ catalyst $(1 \%)$ were used. Fig. 6 showed direct correlation between the stirring rate and ester yield; i.e., as the rate of agitation was increased, an increase in yield was observed. Accordingly, mixing rate of $650 \mathrm{rpm}$ afforded the optimum conversion of recovered oil to methyl esters $(98.5 \%)$. The different stirring rates concluded that elevated speeds promoted the homogenization of reactants, leading to higher methyl ester yields, in accordance with earlier studies [34].

Quality of biodiesel: The nature of fatty acids plays an important role on the qualities of biodiesel, the fatty acids were

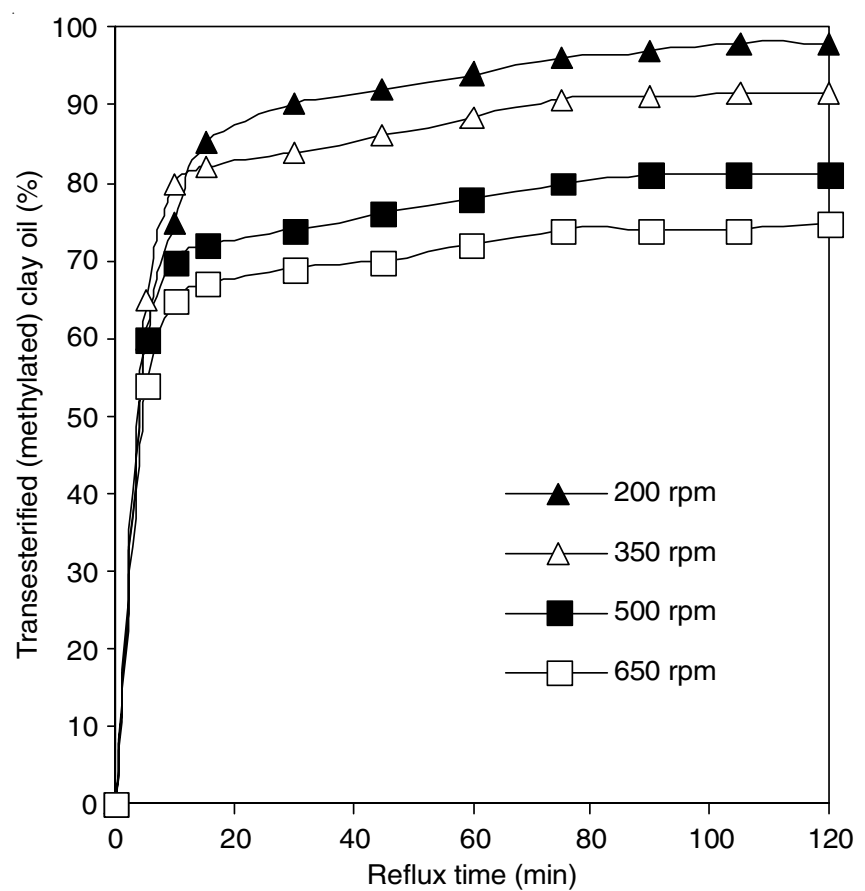

Fig. 6. Stirring effects on CSOR-FAME at $\mathrm{NaOCH}_{3}(1.0 \%)$, oil-methanol molar ratio $(1: 6)$ and reaction temperature $\left(65^{\circ} \mathrm{C}\right)$

analyzed by GLC. The major fatty acid is linoleic acid (53.8 \%), followed by oleic acid $(20.6 \%)$ while palmitic acid $(19.5 \%)$ is the predominant saturated acid. The recovered oil contains saturated fatty acids $(23.8 \%)$, monounsaturated fatty acids $(21.2 \%)$ and polyunsaturated fatty acids $(54.9 \%)$. The transesterified product were purified with solvent extraction, to minimize the impurities, impurities have adverse effects on the fuel properties, especially with regard to temperature performance, increased cloud point, increased pour point and increased kinematic viscosity.

Several important fuel properties are measured according to ASTM methods (Table-4). Although fresh seed oil contains higher contents of triglycerides $(92.5 \%)$ as compare to triglycerides of recovered oil $(88.3 \%)$ but lower contents of mono/diglycerides are present in cotton seed oil. Therefore, higher yield of fatty acids' esters was found out by optimal transesterification of recovered oil as shown in Table-5. The properties of transesterified product by optimal conditions investigated in this study satisfied nearly all prescribed ASTM D 6751 and EN 14214 specifications. Therefore the indigenous activated bleaching clay, abundantly used for processing of cotton seed oil have appreciable contents of fatty acids and after certain optimized processing the product is economical and ecofriendly source of energy.

\section{Conclusion}

The dark coloured cotton seed oil recovered from waste bleaching clay is a potential source of fatty acids for biodiesel production through transesterification of oil. The non-polar solvent extraction yield less amount of oil and lower free fatty acid than standard determination of oil retained in clay, may be due to impurities and higher losses of oil during industrial scaled processing of oil. The base catalyzed transesterification is most efficient by using sodium methoxide as catalyst. Sodium methoxide, offered the highest ester yield (98.5\%) at 
TABLE-4

PROPERTIES OF OPTIMAL METHYLATED PRODUT WITH COMPARISON TO BIODIESEL STANDARDS

\begin{tabular}{|c|c|c|c|}
\hline Property & Biodiesel & ASTM D6751 & EN 14214 \\
\hline Acid value $(\mathrm{mg} \mathrm{KOH} / \mathrm{g})$ & $0.10 \pm 0.03$ & $0.50 \max$ & $0.50 \max$ \\
\hline Density $\left(25^{\circ} \mathrm{C}, \mathrm{kg} \mathrm{m}^{-3}\right)$ & $873 \pm 12.7$ & - & $860-900$ \\
\hline Kinematic viscosity $\left(\mathrm{mm}^{2} / \mathrm{s} ; 40^{\circ} \mathrm{C}\right)$ & $4.03 \pm 0.08$ & $1.9-6.0$ & $3.5-5.0$ \\
\hline Cloud point $\left({ }^{\circ} \mathrm{C}\right)$ & $1.10 \pm 0.11$ & Report & - \\
\hline Pour point $\left({ }^{\circ} \mathrm{C}\right)$ & $1.98 \pm 0.09$ & - & - \\
\hline Flash point $\left({ }^{\circ} \mathrm{C}\right)$ & $154 \pm 3.0$ & $93 \mathrm{~min}$ & $120 \mathrm{~min}$ \\
\hline Ash content $(\%)$ & $0.013 \pm 0.001$ & $0.02 \max$ & $0.02 \max$ \\
\hline Copper strip corrosion $\left(50^{\circ} \mathrm{C}, 3 \mathrm{~h}\right)$ & $1 \mathrm{a}$ & No. 3 max & No. $1 \mathrm{~min}$ \\
\hline Methanol content $(\%)$ & $0.187 \pm 0.002$ & - & $0.20 \max$ \\
\hline Free glycerin $(\%)$ & $0.015 \pm 0.001$ & $0.240 \max$ & $0.250 \max$ \\
\hline Total glycerin $(\%)$ & $0.225 \pm 0.015$ & $0.020 \max$ & $0.020 \max$ \\
\hline Ester contents (\%) & $98.5 \pm 1.26$ & - & $96.5 \mathrm{~min}$ \\
\hline Monoglyceride (\%) & $0.35 \pm 0.04$ & - & $0.80 \max$ \\
\hline Diglyceride (\%) & $0.13 \pm 0.02$ & - & $0.20 \max$ \\
\hline Triglyceride (\%) & $0.07 \pm 0.01$ & - & $0.20 \max$ \\
\hline
\end{tabular}

Values are means of triplicate determinations.

\begin{tabular}{lcc}
\multicolumn{3}{c}{ TABLE-5 } \\
\\
\multicolumn{1}{c}{ FATTY ACIDS OF BIODIESEL } \\
\hline \multicolumn{1}{c}{ Composition } & Symbol & $(\%)$ \\
\hline Myristic acid & $\mathrm{C}_{14: 0}$ & 0.8 \\
Palmitic acid & $\mathrm{C}_{16: 0}$ & 19.5 \\
Palmitoleic acid & $\mathrm{C}_{16: 1}$ & 0.6 \\
Stearic acid & $\mathrm{C}_{18: 0}$ & 2.6 \\
Oleic acid & $\mathrm{C}_{18: 1}$ & 20.6 \\
Linoleic acid & $\mathrm{C}_{18: 2}$ & 53.8 \\
Linolenic acid & $\mathrm{C}_{18: 3}$ & 1.1 \\
Arachidic acid & $\mathrm{C}_{20: 0}$ & 0.4 \\
Behenic acid & $\mathrm{C}_{22: 0}$ & 0.3 \\
Lignoceric acid & $\mathrm{C}_{24: 0}$ & 0.2 \\
\hline Values are means of triplicate determinations.
\end{tabular}

an optimum concentration of $1 \%$. The oil/methanol molar ratio was one of the variables that had the most prevalent influence on the transesterification process. The best results were obtained for (1:6) within the range of molar ratios employed. The optimum temperature $\left(65^{\circ} \mathrm{C}\right)$ and stirring rate $650 \mathrm{rpm}$ proved to be the best for transesterification of cotton seed oil recovered. Important fuel properties of transesterified product were compared well to ASTM D 6751 and EN 14214 specifications, where applicable. Therefore, it may be concluded that tranesterified recoverd oil is an acceptable fuel and waste bleaching clay is an economical resource of fatty acids for transesterifications.

Although, seeds are by product of cotton crop but equally considered a source of edible oil and animal feed. Similarly, waste bleaching clay contains low valued oil but it is a potential source of organics and fatty acids. The bulk density ratio of waste bleaching clay and cotton seed is 700:600 and oil yields are 35 and $39 \%$, respectively. The comparative relation in waste bleaching clay and cotton seed is summarized in Fig. 7. There is not much difference in coordinates of waste bleaching clay and cotton seed interms of weight, density, oil yield, glycerides, free fatty acid and biodiesel except cost, the cost of raw seeds is about fifteen times higher then waste clay. The edible oil production from cotton seed also involves number of processes. Therefore, the production of ecofriendly fuel after transesterification of fatty acids from waste clay is comparatively very cheaper as compare to biofuel from edible cotton seed oil and optimized conditions of transesterifications

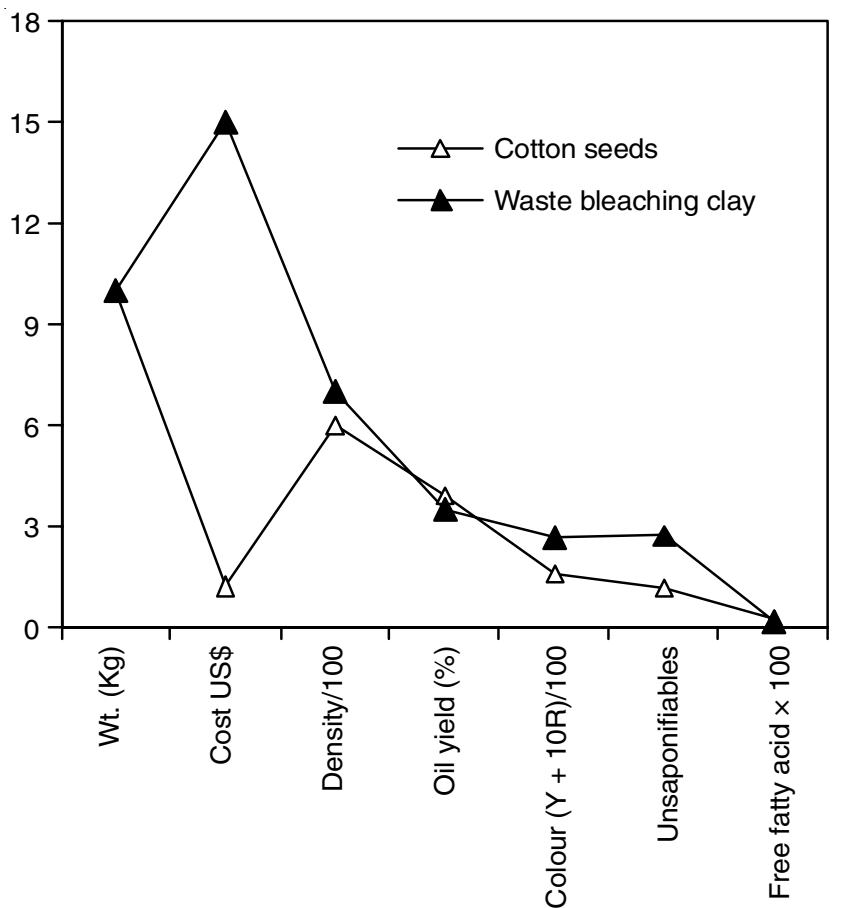

Fig. 7. Comparison of cotton seed and waste bleaching clay and their corresponding oils

are necessary to list out as more economical feed stock. So, waste clay is a potential feed stock of fatty acids and its derivatives (biodiesel). Similarly, the edible oils from cotton seed involve more processing cost as compare to transesterified product from recovered oil.

\section{ACKNOWLEDGEMENTS}

Hamza Vegetable Oil Refinery and Ghee Mills (Pvt) Ltd., Pakistan is acknowledged for providing waste material along with specifications and results.

\section{REFERENCES}

1. G. Antolin, F.V. Tinaut, Y. Briceno, V. Castano, C. Perez and A.I. Ramirez, Bioresour. Technol., 83, 111 (2002).

2. G. Knothe, J.V. Gerpen and J. Krahl, Introduction in the Biodiesel Handbook, AOCS Press, Urbana, IL, pp. 1-3 (2005). 
3. M.M. Gui, K.T. Lee and S. Bhatia, Energy, 33, 1646 (2008).

4. M.J. Haas and T.A. Foglia, Alternate Feedstocks and Technologies for Biodiesel Production, In: The Biodiesel Handbook, AOCS Press, Urbana, IL, pp. 42-61 (2005).

5. X. Meng, J. Yang, Z. Xu, L. Zhang, Q. Nie and M. Xian, Renew. Energy, 34, 1 (2009).

6. Agricultural Statistics of Pakistan, Ministry of Food \& Agriculture, Government of Pakistan, p. 249, Table 169 (2008-09, 2009).

7. T. Mielke, Oil World Annual 2001, ISTA Mielke GmbH, Hamburg, Germany (2001)

8. F.D. Gunstone and J.L. Harwood, The Lipid Handbook, Boca Raton, CRC Press, FL, edn 3 (2007).

9. J.T.L. Ong, J. Am. Oil Chem. Soc., 60, 314 (1983).

10. J.M. Encinar, J.F. Gonzalez and A. Rodriguez-Reinares, Ind. Eng. Chem. Res., 44, 5491 (2005).

11. G. Knothe, J. Am. Oil Chem. Soc., 83, 823 (2006).

12. B. Freedman, E.H. Pryde and T.L. Mounts, J. Am. Oil Chem. Soc., 61, 1638 (1984).

13. M. Çetinkaya and F. Karaosmano'lu, Energy Fuels, 18, 1888 (2004).

14. E. Lotero, Y. Liu, D.E. Lopez, K. Suwannakarn, D.A. Bruce and J.G. Goodwin,, Ind. Eng. Chem. Res., 44, 5353 (2005).

15. D. Royon, M. Daz, G. Ellenrieder and S. Locatelli, Bioresour. Technol., 98, 648 (2007).

16. AOCS, Official and Recommended Practices of the AOCS (1997).

17. Z. Ali, H.L. Siddiqui and S. Mahmud, J. Chem. Soc. Pak., 31, 131 (2009); Z. Ali, H.L. Siddiqui and S. Mahmood, Pak. J. Sci. Ind. Res., 50, 377 (2007).

18. ASTM, American Standards for Testing of Materials (2007).

19. C.G. Lee, C.E. Seng and K.Y. Liew, J. Am. Oil Chem. Soc., 77, 1219 (2000)
20. F.D. Gunstone, Vegetable Oils in Food Technology, Properties and Uses, Blackwell Publishing Composition, CRC Press, USA (2000).

21. R. Alcantara, J. Amores, L. Canoira, E. Fidalgo, M.J. Franco and A. Navarro, Biomass Bioenergy, 18, 515 (2000).

22. J.M. Encinar, J.F. Gonzalez, J.J. Rodriguez and A. Tejedor, Energy Fuels, 16, 443 (2002).

23. M.P. Dorado, E. Ballesteros, F.J. Lopez and M. Mittelbach, Energy Fuels, 18, 77 (2004).

24. Y. Zhang, M.A. Dube, D.D. Mclean and M. Kates, Bioresour. Technol., 90, 229 (2003).

25. F. Ma, L.D. Clements and M.A. Hanna, Trans. Am. Soc. Agric. Eng., 41, 1261 (1998).

26. L.C. Meher, V.S.S. Dharmagadda and S.N. Naik, Bioresour. Technol., 97, 1392 (2006).

27. J.M. Encinar, J.F. González and A. Rodríguez-Reinares, Ind. Eng. Chem. Res., 44, 5491 (2005).

28. H. Fukuda, A. Kondo and H. Noda, J. Biosci. Bioeng., 92, 405 (2001).

29. M.J. Goff, N.S. Bauer, S. Lopes, W.R. Sutterlin and G.J. Suppes, J. Am. Oil Chem. Soc., 81, 415 (2004).

30. N. Usta, Biomass Bioenergy, 28, 77 (2005).

31. J.M. Encinar, J.F. Gonzalez, E. Sabio and M.J. Ramiro, Ind. Eng. Chem. Res., 38, 2927 (1999).

32. F. Karaosmanoglu, A. Akdag and K.B. Cigizoglu, Appl. Biochem. Biotechnol., 61, 251 (1997).

33. F. Ma, L.D. Clements and M.A. Hanna, Bioresour. Technol., 69, 289 (1999).

34. C.L. Peterson, D.L. Reece, R. Cruz and J. Thompson, Proc. Altern. Energy Conf. ASAE, pp. 99-110 (1992). 